\title{
Left-sided primary tumor is a favorable prognostic factor for metastatic colorectal cancer patients receiving surgery
}

\author{
Xiao-Fen Li ${ }^{1, *}$, Yi-Nuo Tan ${ }^{2, *}$, Chen-Han Zhong ${ }^{1, *}$, Li-Zhen Zhu ${ }^{1}$, Xue-Feng Fang ${ }^{1}$, \\ Jun Li ${ }^{2}$, Ke-Feng Ding ${ }^{2,3}$ and Ying Yuan ${ }^{1,3}$ \\ ${ }^{1}$ Department of Medical Oncology, The Second Affiliated Hospital, Zhejiang University School of Medicine, Hangzhou, China \\ ${ }^{2}$ Department of Surgical Oncology, The Second Affiliated Hospital, Zhejiang University School of Medicine, Hangzhou, China \\ ${ }^{3}$ Key Laboratory of Cancer Prevention and Intervention of Ministry of Education, The Second Affiliated Hospital, Zhejiang \\ University School of Medicine, Hangzhou, China \\ *These authors contributed equally to this work
}

Correspondence to: Ying Yuan, email: yuanying1999@zju.edu.cn

Keywords: metastatic colorectal cancer, primary tumor location, surgery

Received: November 14, $2016 \quad$ Accepted: June 12, $2017 \quad$ Published: June 30, 2017

Copyright: Li et al. This is an open-access article distributed under the terms of the Creative Commons Attribution License 3.0 (CC BY 3.0), which permits unrestricted use, distribution, and reproduction in any medium, provided the original author and source are credited.

\section{ABSTRACT}

Objective: The role of surgery in metastatic colorectal cancer ( $\mathrm{mCRC}$ ) remains controversial. This study was performed to assess the impact of surgery on survival in metastatic colorectal cancer.

Materials and Methods: Information of mCRC patients diagnosed between January 1, 2004, and December 31, 2013, was retrieved from the Surveillance, Epidemiology, and End Results Program database. Patients were classified in three groups: patients undergoing resection of both primary and distant metastatic tumors (group 'PMTR'), patients receiving primary tumor resection alone (group 'PTR') and patients not undergoing any surgery (group 'No resection'). Kaplan-Meier method and multivariate Cox proportional hazard regression analysis were applied to estimate disease specific survival time (DSS) and determine prognostic factors.

Results: A total of 38,591 mCRC patients were eligible. Overall, median DSS of group 'PMTR' was significantly longer compared with group 'PTR' and group 'No resection' (28.0 vs 21.0 vs 11.0 months, $P<0.001$ ). Stratified analysis observed that primary tumor in left-sided colorectal cancer (LCRC) was a favorable prognostic factor compared with right-sided colorectal cancer (RCRC) (median DSS of LCRC: PMTR, 34 months, PTR, 25 months, No resection, 13 months; median DSS of RCRC: PMTR, 20 months, PTR, 16 months, No resection, 8 months; $P<0.001$ ). Multivariate analysis demonstrated that surgery was an independent prognostic factor for better survival (PMTR, HR $=0.403,95 \%$ CI 0.384-0.423, $P<0.001 ;$ PTR, HR = 0.515, 95\% CI 0.496-0.534, $P<0.001)$. Furthermore, in patients undergoing surgery, patients with younger age, female, married status, LCRC and lower CEA level were prone to receiving PMTR.

Conclusions: This analysis demonstrated that surgery was an independent prognostic factor for improved survival in MCRC. Patients with LCRC had better survival than patients with RCRC after surgery.

\section{INTRODUCTION}

The statistics of World Health Organization (WHO) have shown that colorectal cancer (CRC) is the third most common malignancy worldwide and the fourth leading cause of cancer-related deaths [1]. According to the Surveillance, Epidemiology, and End Results Program (SEER) cancer statistics, about $20 \%$ of CRC patients have distant metastases at the time of initial diagnosis, with a 5 -year survival rate of $13.1 \%$ [2]. 
The main treatment options for metastatic CRC are surgery, systematic therapy and radiation. For patients with resectable liver and lung metastases, studies indicated that radical resection of primary and metastatic tumors have significant survival benefit [3-6]. Taking liver metastatic $\mathrm{CRC}$ as an example, a recent retrospective study reported a median 5-year survival rate of $38 \%$ in CRC patients with hepatic metastases who had undergone complete resection of primary tumor and liver metastases [7]. Additionally, analysis showed that metastatic CRC (mCRC) patients with solitary liver metastases had a 5-year survival rate as high as 71\% [8]. Therefore, current National Comprehensive Cancer Network (NCCN) guidelines recommend complete resection of resectable liver and lung metastases in suitable mCRC patients $[9,10]$. Undoubtedly, surgery is an effective and vital treatment for mCRC. However, to date, there is no clear definition to 'suitable mCRC patients' for surgery. It is important to find out molecular and clinical predictive factors associated with surgery in $\mathrm{mCRC}$ patients.

It is well known that CRC is a highly heterogeneous disease [11]. Because of different embryonic originations, left-sided CRC (LCRC) is distinguished from rightsided CRC (RCRC) in epidemiology, histology, clinical characteristics and molecular profiles [12, 13]. Some studies indicated that LCRC was a favorable prognostic factor of CRC patients' survival [12, 14]. Recently, primary tumor location of CRC was reported to be associated with the efficacy of cetuximab, a monoclonal antibody targeting epidermal growth factor receptor (EGFR) [15-18]. But to date it is unclear whether primary tumor location is associated with the prognosis of $\mathrm{mCRC}$ patients who have undergone surgical resections.

We conducted this retrospective study to evaluate the impact of surgery on survival in mCRC patients, to investigate prognostic factors for better survival, to identify factors associated with surgery, and especially, to study the role of primary tumor location in the outcome of mCRC patients who underwent surgical resections.

\section{RESULTS}

\section{Patient characteristics}

A total of 38,591 patients newly diagnosed with mCRC from 2004 to 2013 were identified, including 20,857 males and 17,734 females. Patients younger than 70 years old accounted for $69.2 \%$ of the whole cohort. Overall, 6626(17.2\%) patients underwent resection of both primary and distant metastatic tumors (group 'PMTR'), 18,749 (48.6\%) patients received PTR alone (group 'PTR'), and 13216 (34.2\%) patients did not undergo any surgery (group 'No resection'). Metastatic sites and locoregional treatment data have not been recorded in the SEER database until the year of 2010. So we retrieved liver, lung and brain metastases information in patients diagnosed from 2010 to 2013. Patients' demographic and pathological characteristics were summarized in Table 1.

\section{Survival analyses for different groups}

In total, Kaplan-Meier analysis and log-rank (Mantel-Cox) test showed that median disease specific survival (DSS) of group 'PMTR' was significantly longer compared with group 'PTR' and group 'No resection' (28.0 vs 21.0 vs 11.0 months, $P<0.001$, Table 2, Figure 1 ). We could see that median DSS of patients receiving surgery was significantly longer than that of patients who did not undergo any surgery (Figure 1). Stratified analysis observed that LCRC was a favorable prognostic factor compared with RCRC (median DSS of LCRC: PMTR, 34 months, PTR, 25 months, No resection, 13 months; median DSS of RCRC: PMTR, 20 months, PTR, 16 months, No resection, 8 months; $P<0.001$, Figure 2 ). In group 'PMTR', median DSS of patients with LCRC was 14 months longer than that of patients with RCRC (Figure 2A).

Metastatic sites in liver, lung and brain data of patients diagnosed from 2010 to 2013 are available in SEER database. Therefore we further analyzed survival of patients with different sites of metastasis. The results showed that in all the 11,471 patients with liver metastasis, 1,781 (15.5\%) patients received PMTR, 4,810 (41.9\%) patients underwent PTR, and 4,880 (42.6\%) patients were classified to group 'No resection'. Kaplan-Meier analysis found that in patients with liver metastasis, median DSS of group 'PMTR' was significantly longer than the other two groups (PMTR, 32 months, PTR, 22 months, No resection, 12 months; $P<0.001$, Figure 3A). Similar findings were obtained in patients with lung metastasis (PMTR, 25 months, PTR, 20 months, No resection, 12 months; $P<0.01$, Figure 3B). However, in patients with brain metastasis, group 'PMTR' had the same survival time with group 'PTR', but longer than group 'No resection' (PMTR vs PTR, 9 months vs 9 months, $P=0.486$; PMTR vs No resection, 9 months vs 3 months, $P=0.002$, Figure $3 \mathrm{C}$ ).

\section{Prognostic factors for survival}

Multivariate Cox proportional hazard regression analysis identified some independent factors associated with survival. Improved survival or lower death risk was associated with surgery, younger age, LCRC, welldifferentiated tumor, lower CEA level, married status, etc. (Table 2). Surgery was an independent prognostic factor for metastatic CRC patients $(\mathrm{PMTR}, \mathrm{HR}=0.403$, 95\% CI 0.384-0.423, $P<0.001$; PTR, HR $=0.515$, $95 \%$ CI $0.496-0.534, P<0.001)$. In other words, patients who underwent surgery showed significantly decreased death risk compared with those not receiving any surgery. Because the information of metastatic sites was not comprehensive, we did not include sites of metastasis when analyzing prognostic factors. 
Table 1: Characteristics of patients diagnosed with stage IV CRC from 2004 to 2013

\begin{tabular}{|c|c|c|c|c|c|c|}
\hline \multirow{2}{*}{ Variables } & \multicolumn{2}{|c|}{$\operatorname{PMTR}(n=6626)$} & \multicolumn{2}{|c|}{$\operatorname{PTR}(n=18749)$} & \multicolumn{2}{|c|}{ No resection $(n=13216)$} \\
\hline & $n$ & $\%$ & $n$ & $\%$ & $n$ & $\%$ \\
\hline \multicolumn{7}{|l|}{ Age } \\
\hline$<=70$ years old & 4974 & 75.1 & 12784 & 68.2 & 8966 & 67.8 \\
\hline$>70$ years old & 1652 & 24.9 & 5965 & 31.8 & 4250 & 32.2 \\
\hline \multicolumn{7}{|l|}{ Gender } \\
\hline Female & 3527 & 53.2 & 8585 & 45.8 & 5622 & 42.5 \\
\hline Male & 3099 & 46.8 & 10164 & 54.2 & 7594 & 57.5 \\
\hline \multicolumn{7}{|l|}{ Marital status } \\
\hline Married & 3813 & 57.5 & 10332 & 55.1 & 6309 & 47.7 \\
\hline Single/Divorced/Separated/Widowed & 2585 & 39.0 & 7787 & 41.5 & 6277 & 47.5 \\
\hline Unknown & 228 & 3.5 & 630 & 3.4 & 630 & 4.8 \\
\hline \multicolumn{7}{|l|}{ Primary tumor site } \\
\hline RCRC & 2778 & 41.9 & 8433 & 45.0 & 3971 & 30.0 \\
\hline LCRC & 3848 & 58.1 & 10316 & 55.0 & 9245 & 70.0 \\
\hline \multicolumn{7}{|l|}{ Grade } \\
\hline Well-differentiated & 239 & 3.6 & 756 & 4.0 & 593 & 4.5 \\
\hline Moderate-differentiated & 4196 & 63.3 & 11709 & 62.5 & 6062 & 45.9 \\
\hline Poor-differentiated & 1651 & 24.9 & 5004 & 26.7 & 1922 & 14.5 \\
\hline Undifferentiated & 247 & 3.7 & 527 & 2.8 & 107 & 0.8 \\
\hline Unknown & 293 & 4.4 & 753 & 4.0 & 4532 & 34.3 \\
\hline \multicolumn{7}{|l|}{ CEA } \\
\hline Positive/outside reference range & 3588 & 54.2 & 9974 & 53.2 & 8332 & 63.0 \\
\hline Negative/within reference range & 1105 & 16.7 & 2684 & 14.3 & 1032 & 7.8 \\
\hline Unknown & 1933 & 29.2 & 6091 & 32.5 & 3852 & 29.1 \\
\hline \multicolumn{7}{|l|}{ T-stage* } \\
\hline $\mathrm{T} 1$ & 103 & 1.6 & 403 & 2.1 & 2469 & 18.7 \\
\hline $\mathrm{T} 2$ & 178 & 2.7 & 541 & 2.9 & 178 & 1.3 \\
\hline $\mathrm{T} 3$ & 3694 & 55.8 & 11105 & 59.2 & 1864 & 14.1 \\
\hline $\mathrm{T} 4$ & 2532 & 38.2 & 6367 & 34.0 & 2108 & 16.0 \\
\hline $\mathrm{Tx}$ & 119 & 1.8 & 333 & 1.8 & 6597 & 49.9 \\
\hline \multicolumn{7}{|l|}{ N-stage* } \\
\hline 0 & 1180 & 17.8 & 3412 & 18.2 & 5457 & 41.3 \\
\hline 1 & 2354 & 35.5 & 6169 & 32.9 & 3259 & 24.7 \\
\hline 2 & 3003 & 45.3 & 8884 & 47.4 & 487 & 3.7 \\
\hline $\mathrm{Nx}$ & 89 & 1.3 & 284 & 1.5 & 4013 & 30.4 \\
\hline \multicolumn{7}{|l|}{ Liver metastasis } \\
\hline Positive & 1781 & 26.9 & 4810 & 25.7 & 4880 & 36.9 \\
\hline Negative & 793 & 12.0 & 1809 & 9.6 & 1200 & 9.1 \\
\hline Unknown & 4052 & 61.2 & 12130 & 64.7 & 7136 & 54.0 \\
\hline \multicolumn{7}{|l|}{ Lung metastasis } \\
\hline Positive & 280 & 4.2 & 1246 & 6.6 & 2149 & 16.3 \\
\hline Negative & 2271 & 34.3 & 5287 & 28.2 & 3785 & 28.6 \\
\hline Unknown & 4075 & 61.5 & 12216 & 65.2 & 7282 & 55.1 \\
\hline \multicolumn{7}{|l|}{ Brain metastasis } \\
\hline Positive & 31 & 0.5 & 50 & 0.3 & 81 & 0.6 \\
\hline Negative & 2506 & 37.8 & 6462 & 34.5 & 5827 & 44.1 \\
\hline Unknown & 4089 & 61.7 & 12237 & 65.3 & 7308 & 55.3 \\
\hline
\end{tabular}

Note: *In the 'No resection' group, the reported T and N stage have been clinically evaluated based on imaging techniques. Abbreviations: CRC, colorectal cancer; PMTR, resection of both primary and distant metastatic tumors; PTR, primary tumor resection; CEA, carcinoembryonic antigen. 
Table 2: Multivariate analysis for prognostic factors associated with disease specific survival

\begin{tabular}{|c|c|c|c|}
\hline Variable & HR & $95 \% \mathrm{CI}$ & $P$ \\
\hline \multicolumn{4}{|l|}{ Age } \\
\hline$>70$ years old & 1 & & \\
\hline$<=70$ years old & 0.626 & $0.604-0.648$ & $<0.001$ \\
\hline \multicolumn{4}{|l|}{ Gender } \\
\hline Male & 1 & & \\
\hline Female & 0.995 & $0.979-1.011$ & 0.508 \\
\hline \multicolumn{4}{|l|}{ Marital status } \\
\hline Married & 1 & & \\
\hline Single/Divorced/Separated/Widowed & 1.072 & $1.055-1.090$ & $<0.001$ \\
\hline \multicolumn{4}{|l|}{ Primary tumor site } \\
\hline LCRC & 1 & & \\
\hline RCRC & 1.374 & $1.330-1.421$ & $<0.001$ \\
\hline \multicolumn{4}{|l|}{ Grade } \\
\hline Undifferentiated & 1 & & \\
\hline Well-differentiated & 0.756 & $0.711-0.804$ & $<0.001$ \\
\hline Moderate-differentiated & 0.822 & $0.794-0.851$ & $<0.001$ \\
\hline Poor-differentiated & 1.254 & $1.207-1.303$ & $<0.001$ \\
\hline \multicolumn{4}{|l|}{ CEA } \\
\hline Positive/outside reference range & 1 & & \\
\hline Negative/within reference range & 0.649 & $0.622-0.677$ & $<0.001$ \\
\hline \multicolumn{4}{|l|}{ Surgery } \\
\hline No resection & 1 & & \\
\hline PMTR & 0.403 & $0.384-0.423$ & $<0.001$ \\
\hline PTR & 0.515 & $0.496-0.534$ & $<0.001$ \\
\hline
\end{tabular}

Abbreviations: HR, hazard ratio; CI, confidence interval; PMTR, resection of both primary and distant metastatic tumors; PTR, primary tumor resection; CEA, carcinoembryonic antigen.

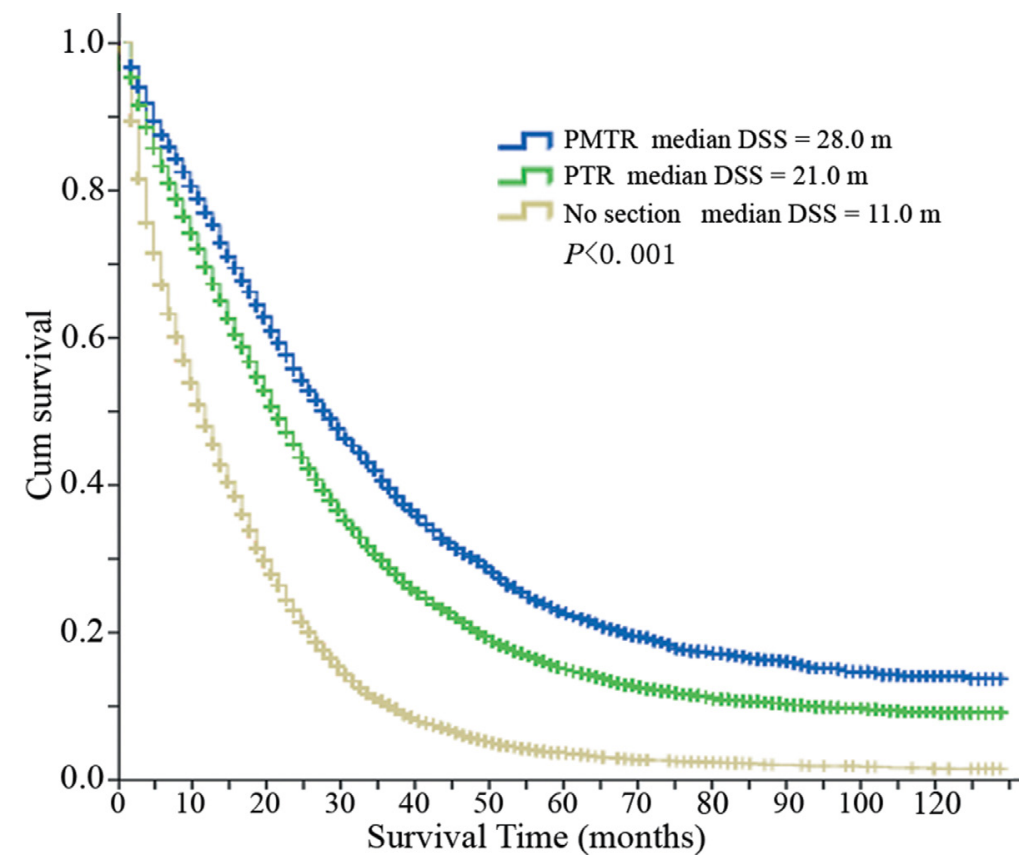

Figure 1: Disease specific survival curves of different groups. Median DSS of group 'PMTR' $=28.0$ months, median DSS of group 'PTR' $=21.0$ months, and median DSS of group 'No resection' $=11.0$ months, $P<0.001$. Abbreviations: DSS, disease specific survival; PMTR, resection of both primary and distant metastatic tumors; PTR, primary tumor resection. 


\section{Factors associated with surgery}

Results of logistic regression analysis demonstrated that patients with younger age, female, married status, RCRC and lower CEA level were more likely to undergo surgery (Table 3). Furthermore, in patients receiving surgery (PMTR or PTR), patients with younger age, female, married status, LCRC and lower CEA level were prone to receiving PMTR (Table 4), while patients with older age, male, unmarried status (single/divorced/ separated/widowed), RCRC and higher CEA level were more likely to receive PTR.

\section{DISCUSSION}

This retrospective cohort study indicated that median DSS of patients receiving surgery, especially those who received both metastasectomy and PTR, was significantly longer than that of patients who did not undergo any surgery (28.0 vs 21.0 vs 11.0 months, $P<0.001)$. Specifically, patients of LCRC had better survival compared with patients of RCRC, especially in surgically resected setting (median DSS of LCRC: PMTR, 34 months, PTR, 25 months, No resection, 13 months; median DSS of RCRC: PMTR, 20 months, PTR, 16 months, No resection, 8 months; $P<0.001$ ). Furthermore, patients with liver and lung metastasis benefited from PMTR if it was feasible, but in patients with brain metastasis, group 'PMTR' had similar survival to group 'PTR'. Multivariate analysis demonstrated that surgery was an independent prognostic factor for improved survival or decreased death risk (PMTR, HR $=0.403$, 95\% CI 0.384-0.423, $P<0.001$; PTR, HR $=0.515$, $95 \%$ CI $0.496-0.534, P<0.001)$. Furthermore, logistic

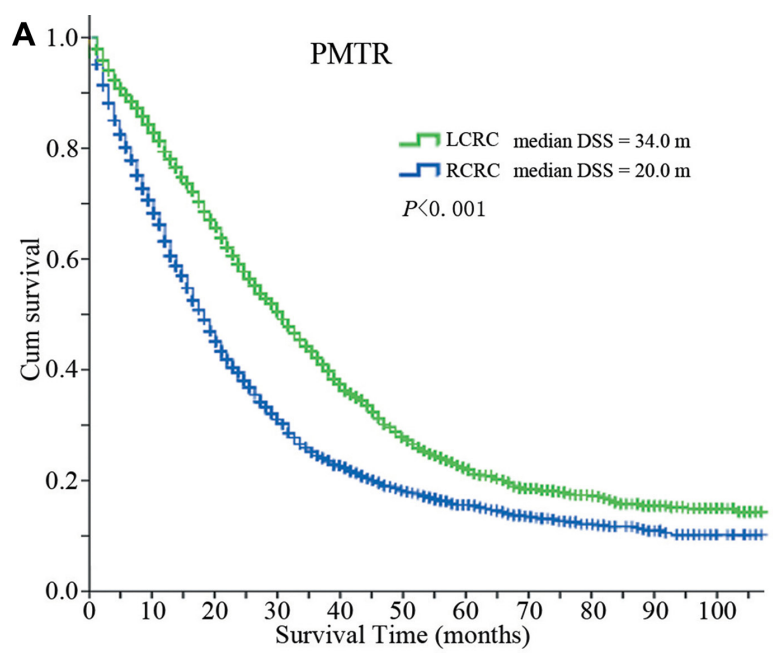

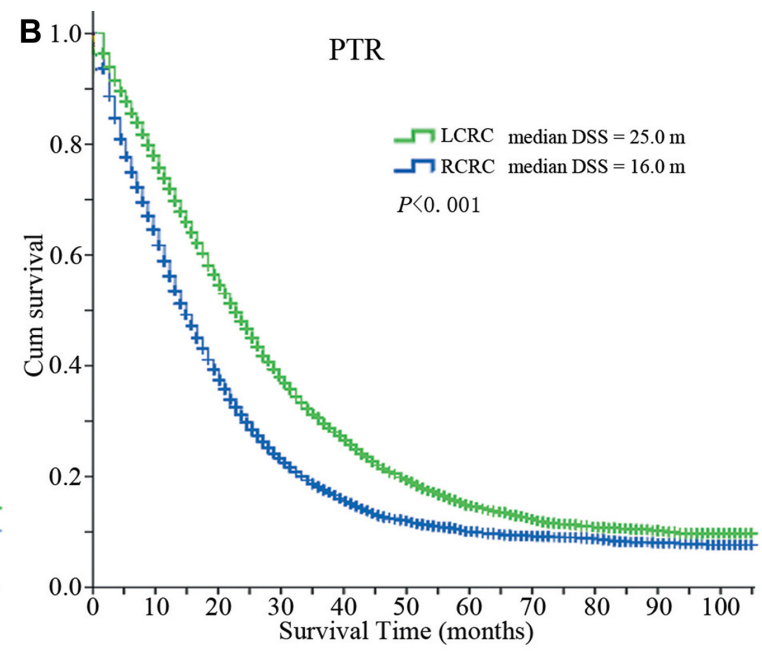

No resection

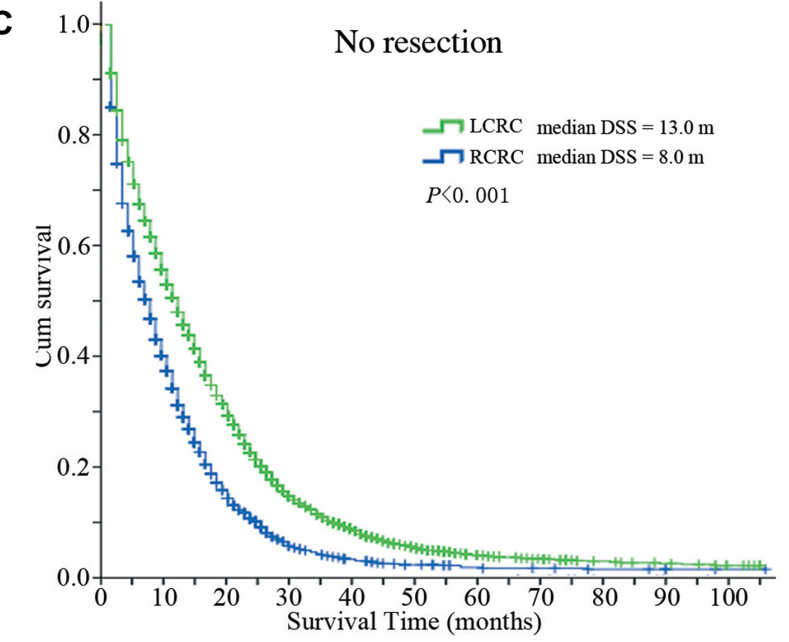

Figure 2: Disease specific survival curves of patients with different primary tumor locations. (A) Disease specific survival curves of patients with different primary tumor locations in group 'PMTR' (median DSS, LCRC $=34.0$ months, RCRC $=20.0$ months, $P<0.001$ ). (B) Disease specific survival curves of patients with different primary tumor locations in group 'PTR' (median DSS, LCRC $=25.0$ months, $\mathrm{RCRC}=16.0$ months, $P<0.001) .(\mathrm{C})$ Disease specific survival curves of patients with different primary tumor locations in group 'No resection' (median DSS, LCRC $=13.0$ months, RCRC $=8.0$ months, $P<0.001$ ). Abbreviations: DSS, disease specific survival; PMTR, resection of both primary and distant metastatic tumors; PTR, primary tumor resection; LCRC, left-sided colorectal cancer; RCRC, right-sided colorectal cancer. 
Table 3: Logistic regression analysis of factors associated with surgery

\begin{tabular}{|c|c|c|c|}
\hline Variables & OR & $95 \% \mathrm{CI}$ & $P$ \\
\hline \multicolumn{4}{|l|}{ Age } \\
\hline$>70$ years old & 1 & & \\
\hline$<=70$ years old & 1.124 & $1.050-1.204$ & 0.001 \\
\hline \multicolumn{4}{|l|}{ Gender } \\
\hline Male & 1 & & \\
\hline Female & 1.247 & $1.172-1.328$ & $<0.001$ \\
\hline \multicolumn{4}{|l|}{ Marital status } \\
\hline Married & 1 & & \\
\hline $\begin{array}{l}\text { Single/Divorced/Separated/ } \\
\text { Widowed }\end{array}$ & 0.730 & $0.686-0.776$ & $<0.001$ \\
\hline \multicolumn{4}{|l|}{ Primary tumor site } \\
\hline LCRC & 1 & & \\
\hline $\mathrm{RCRC}$ & 1.967 & $1.840-2.103$ & $<0.001$ \\
\hline \multicolumn{4}{|l|}{ Grade } \\
\hline Undifferentiated & 1 & & \\
\hline Well-differentiated & 0.229 & $0.172-0.307$ & $<0.001$ \\
\hline Moderate-differentiated & 0.381 & $0.293-0.496$ & $<0.001$ \\
\hline Poor-differentiated & 0.431 & $0.329-0.564$ & $<0.001$ \\
\hline \multicolumn{4}{|l|}{ CEA } \\
\hline Positive/outside reference range & 1 & & \\
\hline Negative/within reference range & 1.954 & $1.790-2.134$ & $<0.001$ \\
\hline
\end{tabular}

Abbreviations: PMTR, resection of both primary and distant metastatic tumors; OR, odds ratio; CI, confidence interval; CEA, carcinoembryonic antigen.

regression analysis revealed that patients with younger age, female, married status, LCRC and lower CEA level were more likely to undergo PMTR.

As we mentioned above in the introduction section, studies demonstrated that hepatic and pulmonary metastasectomy had significant survival benefits to suitable patients [3-8]. With radical resection of metastatic and primary tumors, 5-year survival rate of liver metastatic CRC patients improved from $13.1 \%$ to $38 \%[2,7]$. Unfortunately, over $80 \%$ of patients with stage IV disease present with unresectable metastases [19]. In those cases, the role of palliative PTR remains controversial. A recent retrospective study in the USA showed that the annual rate of PTR decreased from $74.5 \%$ in 1988 to $57.4 \%$ in 2010 $(P<0.001)$, while median relative survival rate improved from $8.6 \%$ in 1988 to $17.8 \%$ in $2009(P<0.001)$ [20]. Yun et al. conducted a study to investigate the prognostic role of PTR in asymptomatic unresectable mCRC patients. Their results showed that palliative PTR was not associated with better survival compared with nonresection after propensity score matching (5-year survival rate, $4.9 \%$ vs $3.5 \%, P=0.27$ ) [21]. However, some studies indicated that PTR was beneficial to the survival of mCRC patients [22-27]. A study including 834 asymptomatic or minimally symptomatic patients diagnosed with stage IV CRC performed by Ahmed et al. showed that patients receiving palliative PTR had improved overall survival compared with non-resection group (19.7 vs 8.4 months, $P<0.0001)$. And PTR was an independent prognostic factor correlated with superior survival ( $\mathrm{HR}=0.47,95 \% \mathrm{CI}$ 0.39-0.57) [24]. In some studies about the value of PTR, the symptoms of primary tumor were unknown $[22,23,25]$. A pooled analysis of individual data from four randomized trials conducted by Faron et al. revealed that PTR was independently associated with better $\mathrm{OS}(\mathrm{HR}=0.63$, $95 \%$ CI $0.53-0.75 ; P<0.001)$ in mCRC patients with unresectable metastases [22]. Tarantino et al. conducted a retrospective cohort study based on SEER registry, and found that PTR was associated with a significantly improved OS ( $n=37793$, HR $=0.40,95 \%$ CI $0.39-0.42$, $P<0.001)$ and cancer-specific survival (HR $=0.39,95 \% \mathrm{CI}$ $0.38-0.40, P<0.001)$ in incurable stage IV CRC patients [25]. Similar to those reported studies, our results also demonstrated the survival benefit of surgeries including PMTR and PTR in $\mathrm{mCRC}$ patients.

Furthermore, our study revealed that LCRC was a favorable prognostic factor compared with RCRC. In PMTR group, patients with LCRC had 14 months longer 
DSS than patients with RCRC. In 2008, Meguid et al. [14] conducted a population-based study to compare the survival of right- and left-sided colon cancers. Their results showed that left-sided colon cancers had a better prognosis than right-sided colon cancers (median OS, 89 months vs 78 months, $P<0.001)$. Recently, some studies demonstrated that LCRC was a good predictive factor for cetuximab efficacy [15-18]. In 2014, Von Einem and his colleagues [15] reanalyzed the data of AIO KRK-0104 trial to investigate the impact of primary tumor site on efficacy of cetuximab in mCRC patients. Their results suggested that in $K R A S$ wild-type patients treated with cetuximab and chemotherapy, left-sided primary tumors were associated with significantly longer OS compared to right-sided primary tumors (26.3 vs 14.8 months, $P=0.016, \mathrm{HR}=0.63)$. In 2016, Chen et al. [18] published the results of a nationwide cohort study, which rerolled $969 \mathrm{mCRC}$ patients with $K R A S$ wild type receiving cetuximab as third-line treatment. Similarly, their results demonstrated that left-sided primary tumor was a favorable predictor of improved cetuximab efficacy in $K R A S$ wild type patients (median OS of patients with left-sided primary tumors and right-sided primary tumors, 12.2 vs 8.07 months, $P<0.001)$. Up to now, the reason for the different survival and clinical behavior between LCRC and RCRC remains unclear. In embryonic origination, LCRC is developed from hindgut, while RCRC is developed from midgut. Therefore it is speculated that differences in embryonic origin and fecal exposure are closely related to the different biological behaviors of LCRC and RCRC. Some studies have revealed that gene expression of LCRC is vastly different from that of RCRC $[13,28]$. For example, the frequencies of microsatelliteinstability high (MSI-H) phenotype and $K R A S$ mutant type in RCRC are higher than those in LCRC. Furthermore, the tumorigenesis mechanism also varies according to different primary site. Comprehensive study on the exact mechanisms of different clinical and biological behaviors
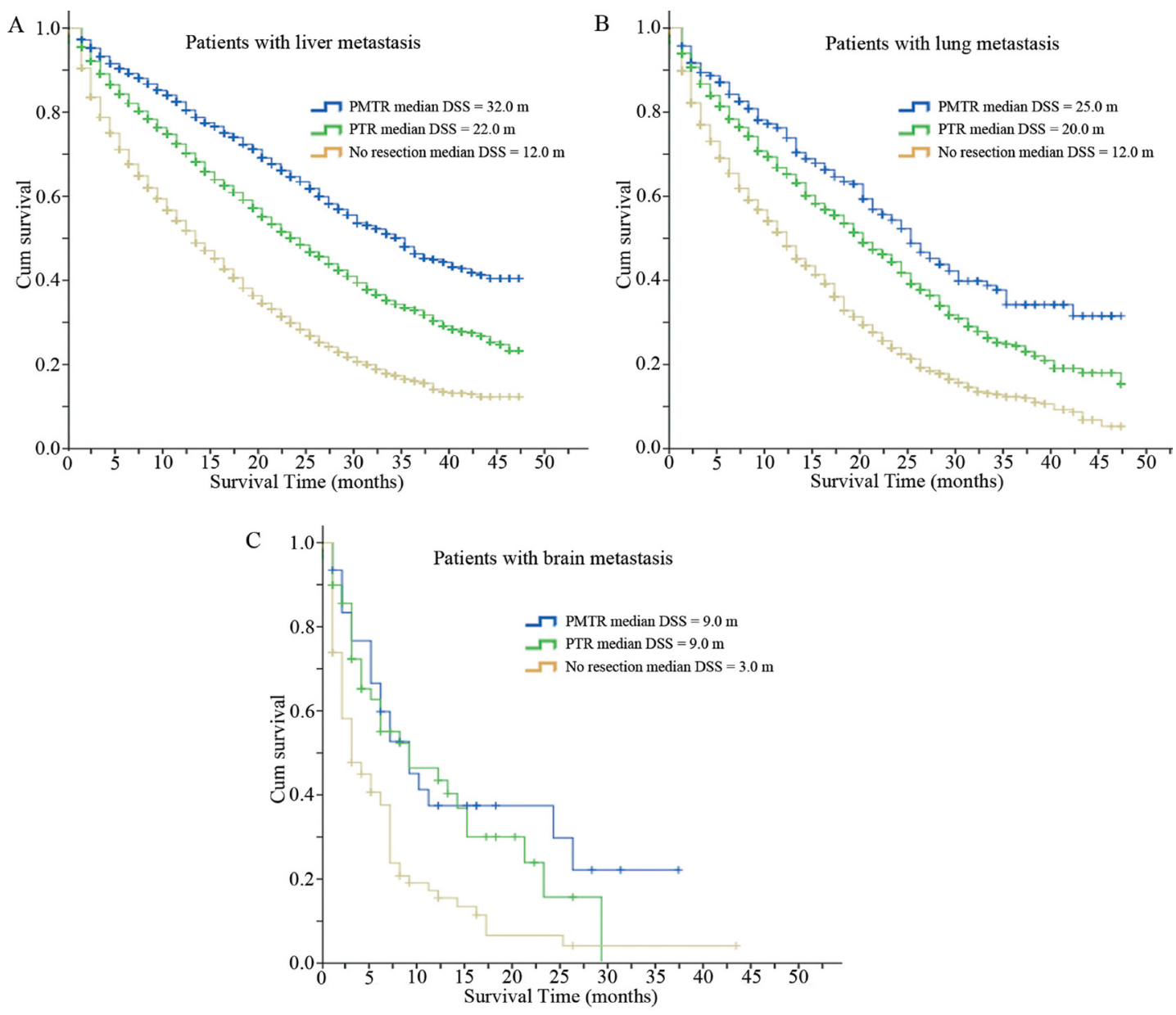

Figure 3: Disease specific survival curves of patients with different sites of metastasis. (A) Disease specific survival curves of patients with liver metastasis (PMTR, 32 months, PTR, 22 months, No resection, 12 months; $P<0.001$ ). (B) Disease specific survival curves of patients with lung metastasis (PMTR, 25 months, PTR, 20 months, No resection, 12 months; $P<0.01$ ). (C) Disease specific survival curves of patients with brain metastasis (PMTR vs PTR, 9 months vs 9 months, $P=0.486$; PMTR vs No resection, 9 months vs 3 months, $P=0.002$ ). Abbreviations: DSS, disease specific survival; PMTR, resection of both primary and distant metastatic tumors; PTR, primary tumor resection. 
Table 4: Logistic regression analysis of factors associated with PMTR

\begin{tabular}{|c|c|c|c|}
\hline Variables & OR & $95 \% \mathrm{CI}$ & $P$ \\
\hline \multicolumn{4}{|l|}{ Age } \\
\hline$>70$ years old & 1 & & \\
\hline$<=70$ years old & 1.385 & $1.277-1.502$ & $<0.001$ \\
\hline \multicolumn{4}{|l|}{ Gender } \\
\hline Male & 1 & & \\
\hline Female & 1.381 & $1.286-1.482$ & $<0.001$ \\
\hline \multicolumn{4}{|l|}{ Marital status } \\
\hline Married & 1 & & \\
\hline Single/Divorced/Separated/Widowed & 0.884 & $0.823-0.950$ & 0.001 \\
\hline \multicolumn{4}{|l|}{ Primary tumor site } \\
\hline LCRC & 1 & & \\
\hline RCRC & 0.866 & $0.806-0.931$ & $<0.001$ \\
\hline \multicolumn{4}{|l|}{ Grade } \\
\hline Undifferentiated & 1 & & \\
\hline Well-differentiated & 0.650 & $0.500-0.846$ & 0.001 \\
\hline Moderate-differentiated & 0.810 & $0.668-0.983$ & 0.032 \\
\hline Poor-differentiated & 0.747 & $0.612-0.912$ & 0.004 \\
\hline \multicolumn{4}{|l|}{ CEA } \\
\hline Positive/outside reference range & 1 & & \\
\hline Negative/within reference range & 1.170 & $1.076-1.271$ & $<0.001$ \\
\hline
\end{tabular}

Abbreviations: PMTR, resection of both primary and distant metastatic tumors; OR, odds ratio; CI, confidence interval; CEA, carcinoembryonic antigen.

in LCRC and RCRC is warranted, which will do great help to personalized and precise medicine. Our study showed that in PMTR group, median DSS of patients with LCRC was 14 months longer than that of patients with RCRC $(P<0.0001)$, which indicated that doctors might take more aggressive approach when treating $\mathrm{mCRC}$ patients with LCRC.

There are some advantages in our study. Firstly, the large sample size of 38,591 can help reducing sampling error. Besides, this study is based on a real world population, which facilitates improving reliability. However, there exist some limitations too. First of all, the intrinsic methodological limitations of retrospective studies exist in our study as well, including selection bias, potential confounders, etc. Second, the SEER database does not include information about patients' performance status, comorbidities, chemotherapy, and all the sites and numbers of metastases, etc. Similarly, we could not know whether the primary tumor was asymptomatic or not, which may influence the choice of surgery. In addition, since T-stages of patients in group 'No resection' were inaccurate/unknown, most of which were documented as ' $T x$ ', we could not perform stratified analysis by T-stage in group 'No resection'. And it was the same with N-stage.
Finally, the detailed information about surgery, such as the specific site of metastasectomy and surgical margins is not available in the SEER database, which may affect patients' survival and results of our analysis.

\section{MATERIALS AND METHODS}

\section{Patient selection}

The data source of this retrospective cohort study was from the SEER database (SEER*Stat 8.3.2) [29]. The SEER Program of the National Cancer Institute collects data on cancer cases from 18 cancer registries in the United States (US), covering approximately $28 \%$ of the US population. Collected data in the SEER Program includes patient demographics, primary tumor site, tumor histology and stage at initial diagnosis, surgery, radiotherapy, death causes (due to this cancer or not) and survival time. Chemotherapy and personal identifying information are not included. The specific sites of metastasectomy and locoregional treatment data have not been recorded until the year of 2010. In this study, we retrieved liver, lung and brain metastases information in patients diagnosed from 2010 to 2013. 
Patients with histologically confirmed stage IV CRC diagnosed between January 1, 2004, and December 31, 2013, were eligible in our study. All the patients were newly diagnosed with stage IV CRC. In other words, there were no recurrent cases. Histological types were restricted to adenocarcinoma (ICD-O-3, 8010,8020-8022, $8140-8141,8144-8145,8210-8211,8220-8221,8230-$ $8231,8260-8263$ ), mucinous adenocarcinoma (ICD-O-3, $8472,8473,8480,8481)$ and signet ring cell carcinoma (ICD-O-3, 8490). The code of primary tumor surgery is RX summ-Surg Prim site $(1998+)>=30$ and $<=80$. The code of no surgery on primary tumor is RX summSurg Prim site $(1998+)=0$. The code of metastatic tumor surgery is RX Summ-Surg Oth Reg/Dis (2003+)! = None; diagnosed at autopsy. And the code of no surgery on metastatic tumor is RX Summ-Surg Oth Reg/Dis $(2003+)=$ None; diagnosed at autopsy. Group 'PMTR' received both primary and metastatic tumors surgeries; group 'PTR' received only primary tumor surgery; and group 'No resection' did not undergo any surgery. Exclusion criteria included age younger than 18 years or older than 90 years, survival time of less than 1 month after confirmed diagnosis, CRC not the first and only diagnosis of malignant tumor, metastasectomy without PTR, occult CRC (no evidence of primary tumor). The remaining patients were grouped in three subsets: patients who underwent resection of both primary and distant metastatic tumors (group 'PMTR'), patients that received PTR alone (group 'PTR') and patients that did not undergo any surgery (group 'No resection'). In addition, primary tumors located in rectum, sigma, descending colon and the splenic flexure were defined as left-sided colorectal cancer (LCRC), while primary tumors originating from cecum to the distal part of the transverse colon were categorized as right-sided colorectal cancer (RCRC).

\section{Statistical analysis}

Median disease specific survival time (DSS) was estimated with Kaplan-Meier method. Log-rank test was applied to compare survival time of different groups and a multivariate Cox proportional hazard regression model was established to determine the relationship between survival and other factors such as age, sex, marital status, surgery, primary tumor location, differentiation grade, CEA (carcino embryonie antigen) level, et al. Logistic regression analysis was performed to identify factors associated with surgery. Statistical tests were two sided and $P<0.05$ was considered statistically significant. SPSS Statistics 20.0 (IBM, Armonk, NY, USA) was used to perform statistical analysis.

\section{Abbreviations}

WHO, World Health Organization; CRC, colorectal cancer; mCRC, metastatic colorectal cancer; SEER,
Surveillance, Epidemiology, and End Results Program; DSS, disease specific survival; OS, overall survival; PMTR, resection of both primary and distant metastatic tumors; PTR, primary tumor resection; LCRC, left-sided colorectal cancer; RCRC, right-sided colorectal cancer; CEA, carcino embryonie antigen; HR, hazard ratio; CI, confidence interval; OR, odds ratio; MSI-H, microsatelliteinstability high phenotype.

\section{Authors' contributions}

YY and KFD conceived of and designed the study. XFL, YNT and CHZ performed the analyses. LZZ, XFF and JL prepared all tables and figures. XFL and YNT wrote the main manuscript. All authors reviewed the manuscript and approved to the submission.

\section{ACKNOWLEDGMENTS}

The authors acknowledge the National Cancer Institute for providing the SEER dataset.

\section{CONFLICTS OF INTEREST}

The authors declare no competing interests.

\section{FUNDING}

This research was supported by Key Projects in the National Science \& Technology Pillar Program during the Twelfth Five-year Plan Period (No. 2014BAI09B07), the National Natural Science Foundation of China (No. 81101580) and Training Program of the Major Research Plan of the National Natural Science Foundation of China (No. 91229104).

\section{REFERENCES}

1. Torre LA, Bray F, Siegel RL, Ferlay J, Lortet-Tieulent J, Jemal A. Global cancer statistics, 2012. CA Cancer J Clin. 2015; 65:87-108.

2. Howlader N, Noone AM, Krapcho M, Garshell J, Miller D, Altekruse SF, Kosary CL, Yu M, Ruhl J, Tatalovich Z, Mariotto A, Lewis DR, Chen HS, et al. SEER Cancer Statistics Review, 1975-2012, National Cancer Institute. Bethesda, MD, http://seer.cancer.gov/csr/1975_2012/, based on November 2014 SEER data submission, posted to the SEER web site, April 2015. Accessed July, 28:2015.

3. Choti MA, Sitzmann JV, Tiburi MF, Sumetchotimetha W, Rangsin R, Schulick RD, Lillemoe KD, Yeo CJ, Cameron JL. Trends in long-term survival following liver resection for hepatic colorectal metastases. Ann Surg. 2002; 235:759-766.

4. Kanas GP, Taylor A, Primrose JN, Langeberg WJ, Kelsh MA, Mowat FS, Alexander DD, Choti MA, Poston G. 
Survival after liver resection in metastatic colorectal cancer: review and meta-analysis of prognostic factors. Clin Epidemiol. 2012; 4:283-301.

5. Brouquet A, Vauthey JN, Contreras CM, Walsh GL, Vaporciyan AA, Swisher SG, Curley SA, Mehran RJ, Abdalla EK. Improved survival after resection of liver and lung colorectal metastases compared with liver-only metastases: a study of 112 patients with limited lung metastatic disease. J Am Coll Surg. 2011; 213:62-9.

6. Marín C, Robles R, López Conesa A, Torres J, Flores DP, Parrilla P. Outcome of strict patient selection for surgical treatment of hepatic and pulmonary metastases from colorectal cancer. Dis Colon Rectum. 2013; 56:43-50.

7. Blackham AU, Russell GB, Stewart JH 4th, Votanopoulos K, Levine EA, Shen P. Metastatic colorectal cancer: survival comparison of hepatic resection versus cytoreductive surgery and hyperthermic intraperitoneal chemotherapy. Ann Surg Oncol. 2014; 21:2667-74.

8. Aloia TA, Vauthey JN, Loyer EM, Ribero D, Pawlik TM, Wei SH, Curley SA, Zorzi D, Abdalla EK. Solitary colorectal liver metastasis: resection determines outcome. Arch Surg. 2006; 141:460-6.

9. National Comprehensive Cancer Network. NCCN Clinical Practice Guidelines in Oncology: Colon Cancer. V.2.2015. Accessed at www.nccn.org on. 29:2015.

10. National Comprehensive Cancer Network. NCCN Clinical Practice Guidelines in Oncology: Rectal Cancer. V.2.2015. Accessed at www.ncen.org on. July 29, 2015.

11. Greystoke A, Mullamitha SA. How many diseases are colorectal cancer? Gastroenterol Res Pract. 2012; 2012:564741.

12. Benedix F, Kube R, Meyer F, Schmidt U, Gastinger I, Lippert H. Colon/Rectum Carcinomas (Primary Tumor) Study Group. Comparison of 17,641 patients with rightand left-sided colon cancer: differences in epidemiology, perioperative course, histology, and survival. Dis Colon Rectum. 2010; 53:57-64.

13. Azzoni C1, Bottarelli L, Campanini N, Di Cola G, Bader G, Mazzeo A, Salvemini C, Morari S, Di Mauro D, Donadei E, Roncoroni L, Bordi C, Sarli L. Distinct molecular patterns based on proximal and distal sporadic colorectal cancer: arguments for different mechanisms in the tumorigenesis. Int J Colorectal Dis. 2007; 22:115-126.

14. Meguid RA, Slidell MB, Wolfgang CL, Chang DC, Ahuja $\mathrm{N}$. Is there a difference in survival between right- versus leftsided colon cancers? Ann Surg Oncol. 2008; 15:2388-2394.

15. Von Einem JC, Heinemann V, von Weikersthal LF, VehlingKaiser U, Stauch M, Hass HG, Decker T, Klein S, Held S, Jung A, Kirchner T, Haas M, Holch J, et al. Leftsided primary tumors are associated with favorable prognosis in patients with KRAS codon 12/13 wild-type metastatic colorectal cancer treated with cetuximab plus chemotherapy: an analysis of the AIO KRK-0104 trial. J Cancer Res Clin Oncol. 2014; 140:1607-1614.

16. Brulé SY, Jonker DJ, Karapetis CS, O'Callaghan CJ, Moore MJ, Wong R, Tebbutt NC, Underhill C, Yip D,
Zalcberg JR, Tu D, Goodwin RA. Location of colon cancer (right-sided versus left-sided) as a prognostic factor and a predictor of benefit from cetuximab in NCIC CO.17. Eur J Cancer. 2015; 51:1405-1414.

17. Lu HJ, Lin JK, Chen WS, Jiang JK, Yang SH, Lan YT, Lin CC, Chang SC, Teng HW. Primary tumor location is an important predictive factor for wild-type KRAS metastatic colon cancer treated with cetuximab as front-line biotherapy. Asia Pac J Clin Oncol. 2016; 12:207-15.

18. Chen KH, Shao YY, Chen HM, Lin YL, Lin ZZ, Lai MS, Cheng AL, Yeh KH. Primary tumor site is a useful predictor of cetuximab efficacy in the third-line or salvage treatment of KRAS wild-type (exon 2 non-mutant) metastatic colorectal cancer: a nationwide cohort study. BMC Cancer. 2016; $16: 327$.

19. Adam R. Chemotherapy and surgery: new perspectives on the treatment of unresectable liver metastases. Ann Oncol. 2003; 14:ii13-ii16.

20. Hu CY, Bailey CE, You YN, Skibber JM, RodriguezBigas MA, Feig BW, Chang GJ. Time trend analysis of primary tumor resection for stage IV colorectal cancer: less surgery, improved survival. JAMA Surg. 2015; 150:245-251.

21. Yun JA, Huh JW, Park YA, Cho YB, Yun SH, Kim HC, Lee WY, Chun HK. The role of palliative resection for asymptomatic primary tumor in patients with unresectable stage IV colorectal cancer. Dis Colon Rectum. 2014; 57:1049-1058.

22. Faron M, Pignon JP, Malka D, Bourredjem A, Douillard JY, Adenis A, Elias D, Bouché O, Ducreux M. Is primary tumour resection associated with survival improvement in patients with colorectal cancer and unresectable synchronous metastases? A pooled analysis of individual data from four randomised trials. Eur J Cancer. 2015; 51:166-176.

23. Ahmed S, Fields A, Pahwa P, Chandra-Kanthan S, Zaidi A, Le D, Haider K, Reeder B, Leis A. Surgical Resection of Primary Tumor in Asymptomatic or Minimally Symptomatic Patients With Stage IV Colorectal Cancer: A Canadian Province Experience. Clin Colorectal Cancer. 2015; 14:e41-7.

24. Tarantino I, Warschkow R, Worni M, Cerny T, Ulrich A, Schmied BM, Güller U. Prognostic Relevance of Palliative Primary Tumor Removal in 37,793 Metastatic Colorectal Cancer Patients: A Population-Based, Propensity ScoreAdjusted Trend Analysis. Ann Surg. 2015; 262:112-20.

25. Cook AD, Single R, McCahill LE. Surgical resection of primary tumors in patients who present with stage IV colorectal cancer: an analysis of surveillance, epidemiology, and end results data, 1988 to 2000. Ann Surg Oncol. 2005; 12:637-645.

26. Bajwa A, Blunt N, Vyas S, Suliman I, Bridgewater J, Hochhauser D, Ledermann JA, O'Bichere A. Primary tumour resection and survival in the palliative management of metastatic colorectal cancer. Eur J Surg Oncol. 2009; 35:164-167. 
27. Venderbosch S, de Wilt JH, Teerenstra S, Loosveld OJ, van Bochove A, Sinnige HA, Creemers GJ, Tesselaar ME, Mol L, Punt CJ, Koopman M. Prognostic value of resection of primary tumor in patients with stage IV colorectal cancer: retrospective analysis of two randomized studies and a review of the literature. Ann Surg Oncol. 2011; 18:3252-3260.

28. Glebov OK, Rodriguez LM, Nakahara K, Jenkins J, Cliatt J, Humbyrd CJ, DeNobile J, Soballe P, Simon R, Wright G,
Lynch P, Patterson S, Lynch H, et al. Distinguishing right from left colon by the pattern of gene expression. Cancer Epidemiol Biomarkers Prev. 2003; 12:755-762.

29. National Cancer Institute. Surveillance, Epidemiology, and End Results. Available at http://seer.cancer.gov. Accessed. Feb 20, 2017. 